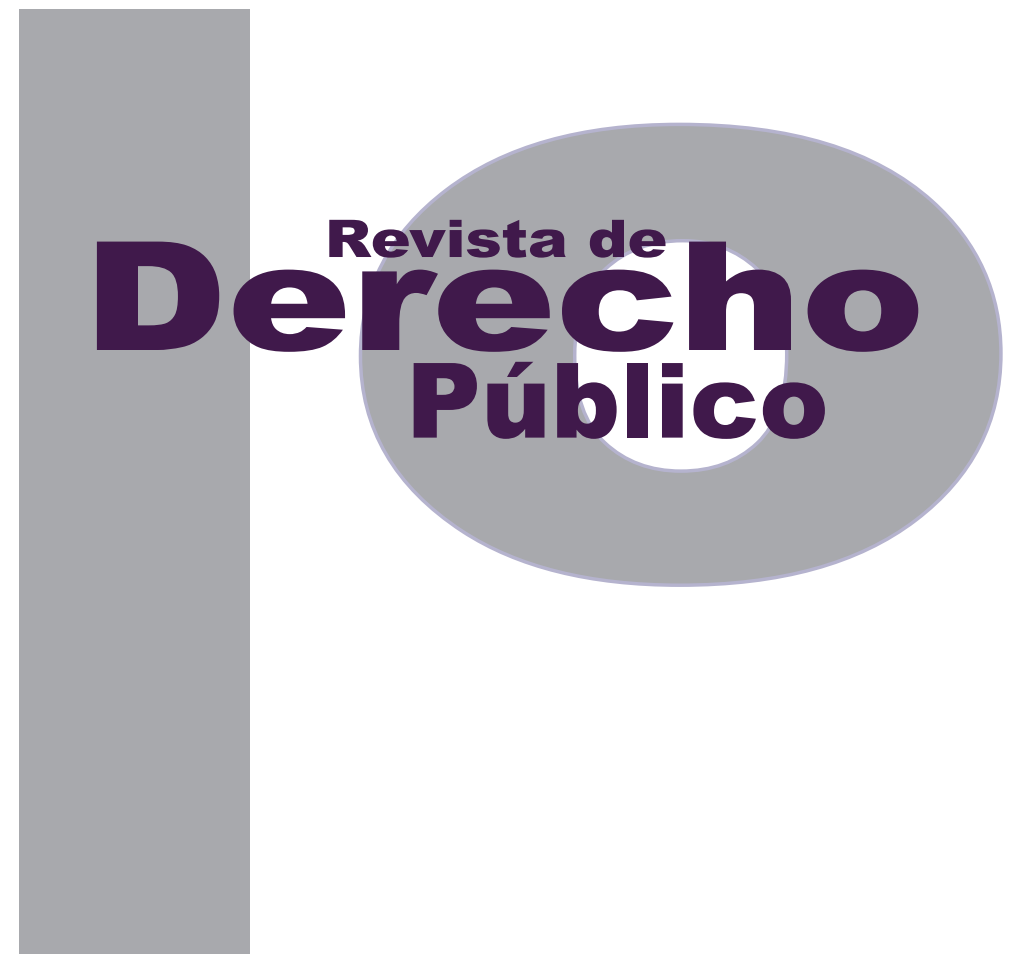

\title{
ESTADO DEL ARTE: DESARROLLO Y VIOLENCIA INTRAFAMILIAR
}

María Alejandra díaz Bernal

Artículo de reflexión

DOI: http://dx.doi.org/10.15425/redepub.33.2014.31

Universidad de los Andes

Facultad de Derecho

Revista de Derecho Público N. ${ }^{\circ} 33$

Julio - Diciembre de 2014. ISSN 1909-7778 


\section{Estado del arte: desarrollo y violencia intrafamiliar}

\section{Resumen}

El presente texto constituye un intento por plasmar los contenidos de la producción académica relacionada con el desarrollo y la violencia intrafamiliar, y a partir de su revisión y exposición desentrañar la relación entre estos dos fenómenos en Colombia. Se pretende mostrar las distintas vertientes de análisis que se han adoptado desde diferentes disciplinas -estudios económicos, teóricos y de políticas públicas-y las cuatro categorías que desde estas se pudieron abstraer para el estudio del tema: i) pobreza y violencia intrafamiliar; ii) educación y violencia intrafamiliar; iii) salud y violencia intrafamiliar; iv) desempleo y violencia intrafamiliar.

Palabras clave: violencia intrafamiliar, desarrollo, educación, pobreza, desempleo, salud, costos.

\section{State of the art: Development and domestic violence}

\section{Abstract}

This work attempts to capture and illustrate the academic production associated with domestic violence and development. The scope of this paper is focused on the review and exposure of the existing academic production around the topic in Colombia. Therefore, it is intended to show the different aspects of analysis that have been taken from various disciplines, including: economic studies, political theory and public policy making. Four categories were extracted from these disciplines in order to present the information: i) poverty and domestic violence, ii) education and domestic violence, iii) health and domestic violence, and iv) unemployment and domestic violence. In each category the reader would find the most relevant bibliography related to each topic.

Keywords: domestic violence, development, education, poverty, unemployment, health, costs.

\section{Estado da arte: desenvolvimento e violência intrafamiliar}

\section{Resumo}

O presente texto constitui uma tentativa por modelar os conteúdos da produção acadêmica relacionada com o desenvolvimento e a violência intrafamiliar, e a partir de sua revisão e exposição desentranhar a relação destes dois fenômenos na Colômbia. Pretende-se mostrar as distintas vertentes de análise que se têm adoptado desde diferentes disciplinas - estudos econômicos, teóricos e de políticas públicas - e as quatro categorias que desde estas puderam se abstrair para o estudo do tema: i) pobreza e violência intrafamiliar; ii) educação e violência intrafamiliar; iii) saúde e violência intrafamiliar, e iv) desemprego e violência intrafamiliar.

Palavras-chave: violência intrafamiliar, desenvolvimento, educação, pobreza, desemprego, saúde, custos. 


\title{
Estado del arte: desarrollo y violencia intrafamiliar*
}

\author{
María Alejandra Díaz Bernal**
}

\section{SUMARIO}

Introducción - A. Fuentes consultadas - I. RELACIÓN ENTRE VIOLENCIA INTRAFAMILIAR Y DESARROLLO - II. VIOLENCIA INTRAFAMILIAR Y POBREZA - III. VIOLENCIA INTRAFAMILIAR Y EDUCACIÓN - IV. SALUD Y VIOLENCIA INTRAFAMILIAR - V. DESEMPLEO, PRODUCTIVIDAD LABORAL Y VIOLENCIA INTRAFAMILIAR - VI. ANÁLISIS DE LA ENCUESTA NACIONAL DE DEMOGRAFÍA Y SALUD: AÑOS 2000, 2005 Y 2010 - VII. COSTOS DE LA VIOLENCIA INTRAFAMILIAR EN TÉRMINOS GENERALES PARA COLOMBIA - A. Salud - B. Educación - C. Mercado Laboral - VIII CONCLUSIONES - Referencias.

* Cómo citar este artículo: Díaz Bernal, M. A. (Diciembre, 2014). Estado del arte: desarrollo y violencia intrafamiliar. Revista de Derecho Público, 33. Universidad de los Andes (Colombia).

** Estudiante de Derecho de la Universidad de los Andes, con Opción en Gobierno de la Escuela de Gobierno Alberto Lleras Camargo. Diplomado en Arbitraje de la Cámara de Comercio de Bogotá. Correo: diazbernal.ma@gmail.com 
Introducción

Hablar de desarrollo ${ }^{1}$ puede resultar problemático si se tiene en cuenta todo el contenido político que lleva consigo este concepto. A partir de este han tenido lugar ciertas diferenciaciones como aquellas referentes a países desarrollados y subdesarrollados; a su vez, otros lo han acusado de ser una visión androcentrista y netamente occidental. Sin entrar a hacer un juicio de valor sobre lo anterior, lo cierto es que la era de la globalización ha impuesto unos estándares comunes de convivencia, entre los cuales se encuentra un mundo libre de pobreza, de violencia, con plena educación, con igualdad entre géneros, con buenas prácticas en salud y un medio ambiente sano. Acorde con lo anterior, en nombre del desarrollo se han realizado diversas investigaciones y prácticas encaminadas a lograr estos objetivos que la mayoría de países han reconocido como valiosos.

El presente artículo es un intento por evidenciar cuál es la producción académica existente en Colombia relacionada con el desarrollo y la violencia intrafamiliar, y a partir de la revisión y exposición de la información que hasta el momento se ha producido acercarnos a la conexión entre estos dos fenómenos en Colombia. Se pretende, además, mostrar las distintas vertientes de análisis que se han adoptado desde diferentes disciplinas: estudios económicos, teóricos y de políticas públicas.

1 La noción de desarrollo utilizada en este artículo se explica en la sección I del presente documento: Relación entre violencia intrafamiliar y desarrollo.
Al recopilar y revisar la información existente se hizo ostensible que, hasta el momento, los intentos por tratar de vincular la violencia intrafamiliar (VIF) con el desarrollo han sido muy escasos en el escenario de la academia y de la práctica en Colombia. Lo anterior resulta paradójico si se tiene en cuenta que

en el contexto mundial, la violencia hoy en día, constituye un problema con repercusiones significativas de carácter económico, de bienestar social, de salud y de gobernabilidad; interfiere en las inversiones y disminuye la capacidad de gobernar de las instituciones del Estado. La violencia antes considerada como un problema de patología delictiva, es reconocida hoy, como un problema de desarrollo macroeconómico (Medellín (Antioquia). Programa de Convivencia Ciudadana, 2000, p. 9).

Así pues, la violencia como un fenómeno de carácter general debe empezar a ser atacada desde todas sus expresiones, ${ }^{2}$ entre las cuales este texto se detendrá en la violencia intrafamiliar dado su continuo incremento durante la última década. ${ }^{3}$

Las causas de esta realidad no son puntuales, y en cuanto a sus efectos lo cierto es que en

2 La violencia puede expresarse de diversas maneras. Por ejemplo, se evidencia en el conflicto armado, en el secuestro, en las desapariciones forzadas, en la intimidación escolar, en los homicidios, en la tortura, etc.

3 Desde el 2002 se ha presentado un ascenso continuo de la VIF en Colombia. "La violencia de pareja ocupó el primer lugar de todas las formas de la violencia intrafamiliar con 57.761 registros $(64,3 \%)$, seguida de la violencia entre otros familiares con 16.267 casos $(18,1 \%)$; en tercer lugar, la violencia a niños, niñas y adolescentes con 14.211 casos $(15,8 \%)$ y, por último, la violencia contra personas mayores con 1.568 casos $(1,7 \%)$ " (Instituto Nacional de Medicina Legal, 2011). 
los cálculos nacionales ${ }^{4}$ se ha prescindido de la inclusión de los costos de la viF, que para nada son despreciables pues tienen un impacto importante en la economía colombiana. Costos entre los cuales se consideran: Ios causados en razón a la atención de la VIF y los ingresos dejados de percibir como consecuencia del mismo fenómeno.

Para el caso colombiano no existen evaluaciones completas sobre los costos de la VIF, solo se encuentran estimaciones globales sobre los costos económicos de la violencia en general (DNP, BID y Universidad de los Andes, 2004, p. 3). Sin embargo, es posible recoger algunos datos aislados de investigaciones importantes, como la adelantada por Ribero y Sánchez (2004) desde el Centro de Estudios sobre Desarrollo Económico (CEDE) de la Universidad de los Andes, (la cual se analizará más adelante), que ayuda a cuantificar el fenómeno. Por ejemplo, Alejandro Gaviria y Carlos Eduardo Vélez (2001) encontraron que en Colombia la VIF afecta a más de la mitad de la población, mientras que la violencia común afecta a cerca del 10\%. De igual manera, de un estudio realizado por la organización MEASURE DHS+, se puede concluir que entre los nueve países que participaron en la investigación, ${ }^{5}$ Colombia tiene los más altos índices de vif y ocupa los primeros lugares (Kishor y Johnson, 2004).

$4 \quad$ Entre los cálculos nacionales que se estudiaron para incluir en este capítulo se encuentran los presupuestos de: la Fiscalía General de la Nación, Bienestar Familiar, Medicina Legal y el Presupuesto General de la Nación.

5 Cambodia (2000), Colombia (2000), República Dominicana (2002), Egipto (2002), Haití (2000), India (1999), Nicaragua (1998), Perú (2000) y Zambia (2002).
Las afirmaciones anteriores constatan el alto costo social y económico para Colombia, que como ya se dijo, incluye los gastos en los que se incurre para atender la VIF y los recursos que se dejan de producir como consecuencia de esta. Así pues, el presente artículo tratará de evidenciar, no sin dificultad, qué dice la literatura acerca del impacto de la VIF en los distintos campos de los que se ocupa el desarrollo, y su determinación ya sea como causa o como consecuencia de los problemas socioeconómicos que hoy en día aquejan al país.

\section{A. Fuentes consultadas}

El Banco Mundial propone diez categorías de índices para evaluar el grado de desarrollo de un país. De estas, como estrategia metodológica para el presente estudio se seleccionaron cuatro: pobreza, educación, salud y empleo. Estas categorias, además de ser entendidas como medidas de bienestar en los hogares, son las más referenciadas en la literatura encontrada sobre el tema que nos ocupa.

Igualmente, esta literatura plantea estudiarlas desde la identificación de: costos directos, costos no monetarios, efectos multiplicadores económicos y efectos multiplicadores sociales. De acuerdo con Vylder (2005), los directos son los monetarios, los cuales aprecian el valor de los bienes y servicios necesarios para tratar y prevenir la vIF; los no monetarios, son aquellos impactos al deterioro de la salud que no generan necesariamente una demanda por servicios médicos (incluye la pérdida de años en vida saludable); los efectos multiplicadores económicos, 
implican una menor participación de la mujer en el mercado laboral, menor productividad en el trabajo, mayor ausentismo, menores ingresos y un impacto en la productividad intergeneracional; y finalmente, los efectos multiplicadores sociales incluyen la transmisión intergeneracional de la violencia de padres a hijos, la erosión del capital social, el deterioro de la calidad de vida y una menor participación en los procesos democráticos (pp. 16-17).

Habiendo determinado lo anterior, se procedió a recopilar la información existente en distintas bibliotecas del país que tenían bases de datos en línea, como: Universidad de los Andes, Universidad Javeriana, Universidad Nacional de Colombia, Universidad Externado de Colombia, Universidad de La Sabana, Universidad del Rosario, Universidad Jorge Tadeo Lozano, Universidad del Norte, Biblioteca Luis Ángel Arango, Biblioteca Julio Mario Santodomingo, Biblioteca Virgilio Barco y Biblioteca Nacional. En estas, se buscó el material bibliográfico que relacionaba la vif con las categorías del desarrollo ya mencionadas, a partir de los siguientes términos de búsqueda: violencia intrafamiliar, violencia intrafamiliar+desarrollo, desarrollo+violencia+familia, violencia intrafa miliar+salud, violencia intrafamiliar+educaci ón, violencia intrafamiliar+empleo y violencia intrafamiliar+pobreza. De los resultados de este procedimiento se extrajo un listado de títulos que contenían las palabras clave de búsqueda y se descartaron los catálogos de la Universidad del Norte, Universidad Jorge Tadeo Lozano y Biblioteca Julio Mario Santodomingo, por no tener títulos relacionados con la búsqueda o por tener catálogos cerrados al público.
También se consultaron varias publicaciones electrónicas con los mismos términos de búsqueda mencionados, que dan cuenta de información actualizada y accesible al público, como fueron: (i) las bases de datos del Banco Interamericano de Desarrollo, la Organización Mundial de la Salud, el Fondo de Desarrollo de las Naciones Unidas para la Mujer (UNIFEM), la Organización Panamericana de la Salud, la Agencia de los Estados Unidos para el Desarrollo Internacional (USAID por sus siglas en inglés), la Red de Investigación en Ciencias Sociales (SSRN por sus siglas en inglés); (ii) los documentos electrónicos del Observatorio de Asuntos de Género de la Alta Consejería Presidencial para la Equidad de la Mujer, la revista electrónica de Estudios Sociales de la Universidad de los Andes, estudios realizados por el Instituto Colombiano para el Fomento de la Educación Superior (ICFES), el Instituto Nacional de Medicina Legal y Ciencias Forenses, el Ministerio de Educación Nacional, la Asociación Probienestar de la Familia Colombiana (Profamilia) y la Oficina del Alto Comisionado para la Paz, así como aquellos obtenidos en bases de datos electrónicas como Heinonline, Justis, Ebsco y Jstor.

Es preciso mencionar que sobre la relación entre VIF y las categorías de desarrollo sugeridas es poco lo que se ha investigado en cada una de ellas, por lo que el desafío consistió en encontrar la información en un sinnúmero de datos desperdigados en distintos artículos, cuyas finalidades no necesariamente iban encaminadas a relacionar la VIF con el desarrollo, ni a encontrar sus costos reales. 
Para el análisis del objetivo planteado, primero se hará una breve reflexión de por qué es importante relacionar la VIF con el desarrollo; en este aparte se expondrá cuál es la teoría del desarrollo aplicada en el presente capítulo, sin dejar de mencionar cuáles son las ventajas y desventajas de adoptar dicha visión. Con esto en mente, se pasará a exponer cada una de las categorías de desarrollo propuestas (pobreza, educación, salud y empleo) en la realidad colombiana. A renglón seguido, se compartirán las últimas cuatro Encuestas Nacionales de Demografía y Salud (ENDS) correspondientes a los años 1995, 2000, 2005 y 2010, estudios que harán evidentes los avances y retrocesos en la prevención y tratamiento de la VIF a nivel nacional. Al Ilegar a este punto se presentarán los costos globales de la VIF para Colombia, y finalmente se procederá a plantear algunas conclusiones sobre la información encontrada.

\section{RELACIÓN ENTRE VIOLENCIA INTRAFAMILIAR Y DESARROLLO}

Sobre la relación entre VIF y desarrollo deben hacerse algunas aclaraciones en cuanto a las discusiones existentes, con miras a adoptar una u otra visión del desarrollo para analizar y solucionar los problemas socioeconómicos de una comunidad. Por un lado, está la posición que afirma que a través del desarrollo se logran plenos e iguales derechos. Por otro lado, están quienes insisten en que el desarrollo perpetúa las desigualdades y las violaciones de derechos humanos, dándole cierta legitimidad a dicha situación. Para explicar adecuadamente lo ante- rior, la presente sección se guiará por el marco teórico del desarrollo propuesto por Helena Alviar, en el libro Derecho, desarrollo y feminismo en América Latina, publicado en el año 2008.

De acuerdo con esta autora, existen tres vertientes principales desde las cuales se concibe el desarrollo. La primera es la del "intervencionismo neoclásico" en donde se encuentran cuatro grupos de teóricos: a) los economistas desarrollistas, b) los que conciben el desarrollo como un equivalente del crecimiento económico, c) los que creen en el Estado como motor de desarrollo y d) los que entienden el desarrollo como un asunto de redistribución. La segunda es la "teoría de la dependencia", representada por los teóricos marxistas ortodoxos, por un lado, y los críticos históricos como se han llamado en este artículo, por el otro. La tercera es la del neoliberalismo, la cual retorna un poco a las premisas propuestas por el intervencionismo neoclásico, razón por la cual se explicarán estas dos vertientes simultáneamente.

Desde el primer grupo de teóricos (intervencionistas neoclásicos y neoliberales), se concibe el desarrollo como una herramienta para lograr plenos derechos. En este modo de pensamiento se puede encuadrar, considerando la relación VIF y desarrollo, a autores como Eleonora Cebotarev, quien afirma que "las consideraciones sobre los derechos humanos se han convertido en poderosas herramientas para el avance del desarrollo, particularmente en su función equitativa de prevenir las injusticias, los abusos y la depravación de las libertades fundamentales" (1994, p. 83-108). Incluso a nivel internacional 
se ha entendido que "el logro de los derechos humanos se considera como indicador de los niveles de desarrollo de las sociedades" (Cebotarev, 1994, p. 84). En esta misma línea argumentativa, entidades internacionales como la Oficina del Alto Comisionado de las Naciones Unidas para los Derechos Humanos (OACDH), encuentra que "tanto los derechos humanos como el desarrollo tienen como propósito promover el bienestar y la libertad sobre la base de la dignidad y la igualdad inalienables de las personas" (2006, p. 14).

Sin embargo, esta visión encuentra oposición por parte de la segunda vertiente propuesta en el marco teórico (teóricos de la dependencia), toda vez que hay quienes sostienen que lo que en realidad ha generado el desarrollo ha sido un descuido en la inversión social y una perpetuación de las prácticas tradicionales que refuerzan fenómenos como el de la VIF. La propia Eleonora Cebotarev expone:

hay evidencia que sugiere que la estructura familiar que predomina en Latinoamérica es una de las principales instituciones que contribuyen a las violaciones de los derechos humanos de las mujeres y que una abrumadora mayoría de las políticas y programas de "desarrollo" no solo no han reducido, sino que han empeorado la situación de dominación masculina. Más aún, "el desarrollo" afecta los roles de género intra-familiares de tal manera que restringe los roles extra-familiares, por ejemplo de las mujeres, y con ello su participación activa en las esferas económicas, políticas, culturales y cívicas a las que tienen derecho (1994, p. 85).
Piénsese por un momento en las consecuencias que se han derivado de las cinco locomotoras de desarrollo que ha propuesto Juan Manuel Santos para su gobierno y en especial aquella de “más empleo". Frente a dicha locomotora, podría afirmarse que la formalización del empleo que se incentiva solo incluye al sector masculino. ¿Por qué? Porque gran parte de la población femenina se encuentra ocupada en labores de cuidado de manera informal y sin remuneración económica. Debido a la gran dificultad que existe para justificar económicamente la labor de cuidado, esta se deja por fuera de los planes de desarrollo del gobierno generando un incremento en la fuerza laboral masculina y subyugando aún más a la mujer, quien queda desprotegida y excluida de los beneficios de los que gozan las labores que el gobierno considera formales. ${ }^{6}$

6 Esto se sustenta en las siguientes cifras del Departamento Administrativo Nacional de Estadística (DANE, agosto 2013):

Para el 2013, el desempleo de las mujeres alcanzó el 12,3\%, mientras que el de los hombres estuvo alrededor del $7,6 \%$.

Para el 2013, "el 61,8\% de los hombres inactivos se dedicó principalmente a estudiar, mientras que el $57,0 \%$ de las mujeres inactivas se dedicó a oficios del hogar" (p. 2) 
Lo anterior se evidencia en la gráfica 1.

\section{Gráfica 1. Tasa de desempleo}

Tasa de desempleo

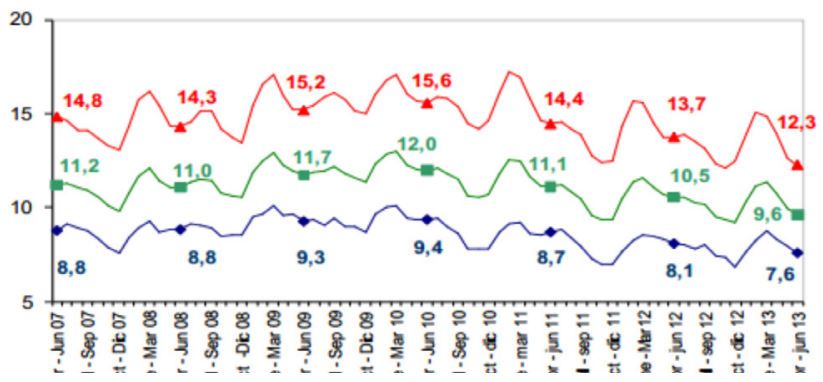

Fuente: DANE (Agosto 2013, p. 4). Boletín de Prensa: Comportamiento del mercado laboral por sexo. Tasa de Desempleo. Recuperado el 2 de septiembre de 2014 de DANE: https://www.dane.gov.co/files/investigaciones/boletines/ech/ech_genero/bol_sexo_abr_jun13.pdf).

Otro ejemplo lo ofrece Helena Alviar en su obra Legal Reform, Social Policy, and Gendered Redistribution in Colombia: The Role of the Family, donde opina que las distintas agendas del desarrollo han logrado, además de distribuir recursos, crear y mantener identidades difíciles de quebrar (2011). ${ }^{7}$ Para desarrollar un poco más la afirmación anterior, la autora hace referencia a las políticas sociales en "pro" del desarrollo, como el programa Familias en Acción, mediante el cual se ha incrementado el trabajo reproductivo ${ }^{8}$ de la mujer fomentando el mantenimiento

7 De acuerdo con esta autora el derecho crea identidades. Estas se definen como patrones, arquetipos o paradigmas que toman tal fuerza que se convierten en una realidad para quien es sujeto de ellas.

8 "Las Conferencias Internacionales de Estadísticas del Trabajo (CIET) de la Organización Internacional del Trabajo (oІT), recomiendan conceptuar la actividad económica, como aquella actividad dirigida a la producción de bienes y servicios, al comercio y otras actividades conexas destinadas al mercado, al trueque $o$ al autoconsumo, este concepto contiene como elemento fundamental, el intercambio de la fuerza de trabajo por dinero o mercancías (especie en bienes o servicios), de lo anterior que, de las actividades del autoconsumo quedan de una resiliencia femenina que evita que esta se empodere y pueda enfrentar, por ejemplo, situaciones de violencia, como en el caso de la vif.

Estas críticas encuentran asidero en los reproches que se le han hecho a la modernidad en cuanto a su enfoque universalista y homogeneizador, que logra eliminar las diferencias, establecer una visión lineal del tiempo y la cultura, así como implantar en la mentalidad de la humanidad una perspectiva androcéntrica de lo que debe ser el progreso. Se ha sugerido que el fracaso y continuo retroceso de los grupos poblacionales más pobres y desfavorecidos se debe a la construcción de programas y políticas que fueron pensadas por y para el ideal de hombre que ha creado la sociedad moderna de Occidente, desatendiendo las verdaderas necesidades de las víctimas (entre las cuales se enmarcan las víctimas de VIF), que cada día se encuentran más lejos de lograr plenos e iguales derechos.

A pesar de lo anterior y debido a la gran dificultad para abstraerse del mundo globalizado en el que nos encontramos, resulta más común hallar dentro de la literatura analizada la tesis en la que se entiende el desarrollo como un esfuerzo por lograr plenos derechos y satisfacción de necesidades básicas, que permitan un mejoramiento en cualquier aspecto: social, económico, cultural y político de un país.

explícitamente excluidas las tareas domésticas propiamente dichas, tales como: cocción de alimentos, lavado de ropa, limpieza de la casa, etc., debido a que no implican un intercambio de fuerza de trabajo por dinero o mercancías" (Gallardo, 2003, p. 2). 
Ahora bien, esta perspectiva de desarrollo debe entenderse como multidimensional, pues pretende abarcar todas las áreas en las que se ve inmiscuido el ser humano. Es por ello que en su análisis deben incluirse todos los problemas que amenazan la obtención de plenos derechos, tales como el de la VIF, problema que permea todas las esferas que afectan a los ciudadanos, como la educación, la salud, la pobreza y el empleo, entre otros. Lo anterior, teniendo presente que debe dirigirse hacía una igualdad real, es decir, una inclusión de la perspectiva de género, evitando a toda costa la tendencia homogeneizadora de la que ha sido acusado el desarrollo, que desconoce a ciertos sectores de la sociedad.

Habiendo expuesto los dos grupos de vertientes (neoliberalismo e intervencionismo neoclásico vs. teoría de la dependencia), resulta importante advertir al lector que se encontrará con que la literatura compilada en este estado del arte unas veces se enmarca dentro de la tesis del neoliberalismo/intervencionismo neoclásico y otras veces dentro de la tesis de la dependencia.

\section{VIOLENCIA INTRAFAMILIAR Y POBREZA}

En este aparte se empezará con el análisis de la pobreza y su relación con la VIF, teniendo en cuenta que el enfoque que se le ha dado desde la perspectiva económica es el de "vIF como una trampa de pobreza". Para ello resulta necesario exponer las dos tesis actuales. Una primera posición expuesta por Claudia Caicedo, en Lucha contra la violencia intrafamiliar, alega que "la violencia intrafamiliar no es patrimonio de la pobreza" (2005, p. 75), toda vez que se encuentra presente en todas las clases o estratos sociales. Según algunos expertos, como la médica psiquiatra Isabel Cuadros, en Colombia la violencia no coincide siempre con las zonas de marginalidad, lo que lleva a pensar que existen muchas más variables que inciden en su producción (Observatorio Asuntos de Género, 2004). En especial, cuando se trata de VIF no puede generalizarse, ya que el fenómeno, al estar en el ámbito privado de la familia es difícil de detectar en los estratos altos en donde la magnitud y frecuencia no ha podido ser registrada.

No obstante, a pesar de lo cierto o convincente que pueda sonar lo anterior, se encuentra en otras investigaciones como la de Robert Lalasz un sustento más fuerte que sostiene la posición contraria, es decir, que la pobreza es uno de los determinantes de la VIF (2004). Bajo esta mirada, se contempla el hecho de que "si bien la VIF tiene como característica la de estar generalizada en todos los grupos y estratos sociales, esta es particularmente aguda en los grupos poblacionales más deprimidos" (Medellín (Antioquia). Programa de Convivencia Ciudadana, 2000, p. 5). Ahora bien, se dice que tiene un mayor sustento, pues la tesis se construye sobre la idea de que la vif está asociada con la dependencia económica y con la falta de recursos.

Esto último está coligado con la línea de desarrollo de la "teoría de la dependencia", donde vale la pena recordar lo que en su momento Raúl Presbisch entendió como dependencia 
cuando analizaba el subdesarrollo de los países del tercer mundo. Presbich insistía en que la razón del subdesarrollo consistía en que quienes tomaban las decisiones importantes acerca de la economía mundial eran los países fuertes económicamente; en este sentido, la falta de poderío económico para poder determinar las decisiones sobre los precios en el mercado hacía que los países de la periferia continuaran siendo pobres y dependientes de las determinaciones de las naciones fuertes. Este razonamiento resulta igualmente aplicable a la situación de las víctimas de VIF cuando analizamos el fenómeno desde la pobreza. Para la persona que es pobre la posibilidad de autodeterminación se ve altamente disminuida, pues depende del músculo económico de otros actores en el mercado e incluso del hogar, lo que la convierte en una víctima de dominación que en muchos casos se expresa como violencia.

Entre los estudios que defienden la hipótesis de la VIF como consecuencia de la dependencia y falta de recursos económicos encontramos: Violencia doméstica: problema de la comunidad y del Estado; Lucha contra la violencia intrafamiliar: perspectivas desde la experiencia colombiana; Who Bears the Burden of Crime in Colombia; Determinantes, efectos y costos de la violencia intrafamiliar; y Mujer, familia y violencia, entre otros.

De los documentos mencionados, resulta interesante resaltar el de Gaviria y Vélez (2001), Who bears the burden of crime in Colombia, en el que se afirma que los pobres soportan una carga desproporcionada de violencia -entre la cual está la VIF -, teniendo en cuenta que el nivel de riqueza determina la probabilidad de ser o no víctimas de un crimen. Esto se dice porque en los hogares ricos existen menores probabilidades de ser víctimas de violencia puesto que tienen más posibilidades de invertir en la prevención de esta. Por su parte, los hogares pobres no pueden gastar en prevención, por lo cual tienden a sufrir más la violencia intrafamiliar. Por ejemplo, “las mujeres en los quintiles más bajos en la distribución de recursos, son un $15 \%$ más propensas a sufrir de violencia intrafamiliar que las mujeres que están en los quintiles más altos" (Gaviria y Vélez, 2001, p. 3).

Los gastos que están relacionados con la prevención de la vif pueden asociarse a la inversión en educación, a la posibilidad de vivir en hogares monoparentales donde se evita tener que convivir con más miembros de la familia como tíos, abuelos, primos, conocidos, etc., quienes en situaciones de estrés pueden incidir en una reacción violenta, o incluso convertirse en agresores en casos de violencia sexual; también podría asociarse con la posibilidad de adquirir mecanismos de planificación familiar -que aunque hoy en día están incluidos en el plan obligatorio de salud (POS), en Colombia continúan siendo los más costosos a nivel de América Latina) - ${ }^{9}$ para evitar el incremento de los miembros de la familia y por consiguiente mayores gastos.

9 Véase: Sarley, D., Dayaratna, V., Abramson, W., Gribble, J. y Quesada, N. (2006). Opciones para la adquisición de anticonceptivos: lecciones aprendidas en Latinoamérica y el Caribe. Arlington, Va.: Deliver y Washington, DC: USAID. 
Otra muestra de lo expuesto son las cifras reveladas por Ribero y Sánchez (2003), en la publicación Determinantes, efectos y costos de la violencia intrafamiliar en Colombia. En dicho estudio se dice que "tomando el índice de activos fijos del hogar como medida de pobreza, se encuentra que en los quintiles bajos, ${ }^{10}$ cerca del $8 \%$ de las mujeres y niños fueron víctimas de algún tipo de maltrato físico" (p. 4).

Ante esta realidad, parte de la literatura se pregunta ¿por qué la pobreza incide en la viF? Kishor y Johnson, en Profiling Domestic Violence: $A$ Multy Country Study, trabajo que incluye a Colombia como objeto de análisis, proponen que

el riesgo de experimentar violencia intrafamiliar está asociado con el número de hijos y el hacinamiento en los hogares, ya que existe menor ingreso per cápita, y los fondos insuficientes contribuyen a los niveles de estrés dentro del hogar, lo cual lleva al uso de la violencia (2004. p. 30).

Esto quiere decir que la pobreza es un catalizador de estrés y de riesgo de violencia al interior de la familia, afectando a los miembros más débiles de su composición, a diferencia de lo que ocurriría en una familia "rica" cuyos miembros a pesar de tener motivos de estrés, la pobreza no es uno de ellos. En conclusión, "en la problemática familiar, aparece como una de las prioridades los problemas económicos que afrontan muchas familias en nuestra sociedad,

10 Los quintiles de activos en un hogar se definen teniendo en cuenta información sobre la posesión de televisor, nevera, acceso a agua potable, electricidad, alcantarillado, teléfono, tipo de combustible utilizado en el hogar, etc. generando conflictos entre las parejas, que a su vez propicia un ambiente de violencia" (Osorio y Arias, 1989. p. 181).

\section{VIOLENCIA INTRAFAMILIAR Y EDUCACIÓN}

En este aparte se abordará la discusión sobre la educación y la VIF desde tres escenarios; el primero, cómo la vif es un problema para el desarrollo de la educación en Colombia; el segundo, cómo el descuido desde el ámbito educativo ha sido cómplice de los maltratos que se generan dentro de la familia; y finalmente, cómo la educación es una herramienta para disminuir los efectos de la vif en la sociedad.

Se empezará examinando el primer escenario, teniendo en cuenta que la vif resulta un obstáculo importante en el mejoramiento de la calidad educativa, especialmente en el caso de la educación pública, dado que en el ámbito de la educación privada no se encontraron datos que explicarán el fenómeno.

El Estado ha destinado cuantiosas sumas para mejorar la calidad educativa en el país. Por ejemplo, para el año 2012, destinó al sector educativo aproximadamente 23 billones de pesos (Ministerio de Educación Nacional, 2012), distribuidos entre el gasto para educación pública, programas de incentivo y mejoramiento de la educación y programas especiales. A pesar de que la cifra es grande, autores como Rubio y Chagüi (2003) consideran que el presupuesto no resulta suficiente, pues aunque cada año 
aumenta, solo incrementa lo estrictamente necesario en relación con la inflación, es decir, no hay un verdadero aumento en la inversión.

No obstante, para el 2013, la Presidencia de la República anunció que la inversión social alcanzaría el $70 \%$ del presupuesto de inversión (40,7 billones de pesos), noticia que a la Redacción Política de El Tiempo (2012) le mereció el calificativo de "inversión récord". De acuerdo con esto, le correspondió a educación 24,4 billones, significando un incremento del $11 \%$ respecto al año anterior, el menor frente a las otras áreas de inversión, si se tiene en cuenta que entre 2010 y 2013 la asignación presupuestal para otros sectores fue: minas, $86 \%$; salud, $81 \%$; vivienda, 71\%; agropecuario, 58\%; transporte, 51\% y, por último, educación con un 29\% (Ministerio de Ha- cienda y Crédito Público [MINHACIENDA], 2013). Sin embargo, se trata de la mayor cifra registrada en la historia colombiana, lo que da esperanzas para el progreso de este sector. Esto mismo se reflejó en el presupuesto del 2014, en que la inversión en educación estuvo alrededor de los 25 billones de pesos para funcionamiento y 2 billones adicionales por concepto de "nueva inversión" (MINHACIENDA, 2014).

A pesar de lo anterior, esta inversión económica pareciera no tener importancia si se miran los estudios estadísticos sobre las pruebas de Estado Saber que periódicamente aplica el Instituto Colombiano para el Fomento de la Educación Superior (ICFES), y que registra la gráfica 2. Como se observa, los resultados a nivel nacional se encuentran por debajo del promedio esperado.

\section{Gráfica 2. Promedio Nacional en Pruebas del Estado en Educación. ICFES (2012-2014)}

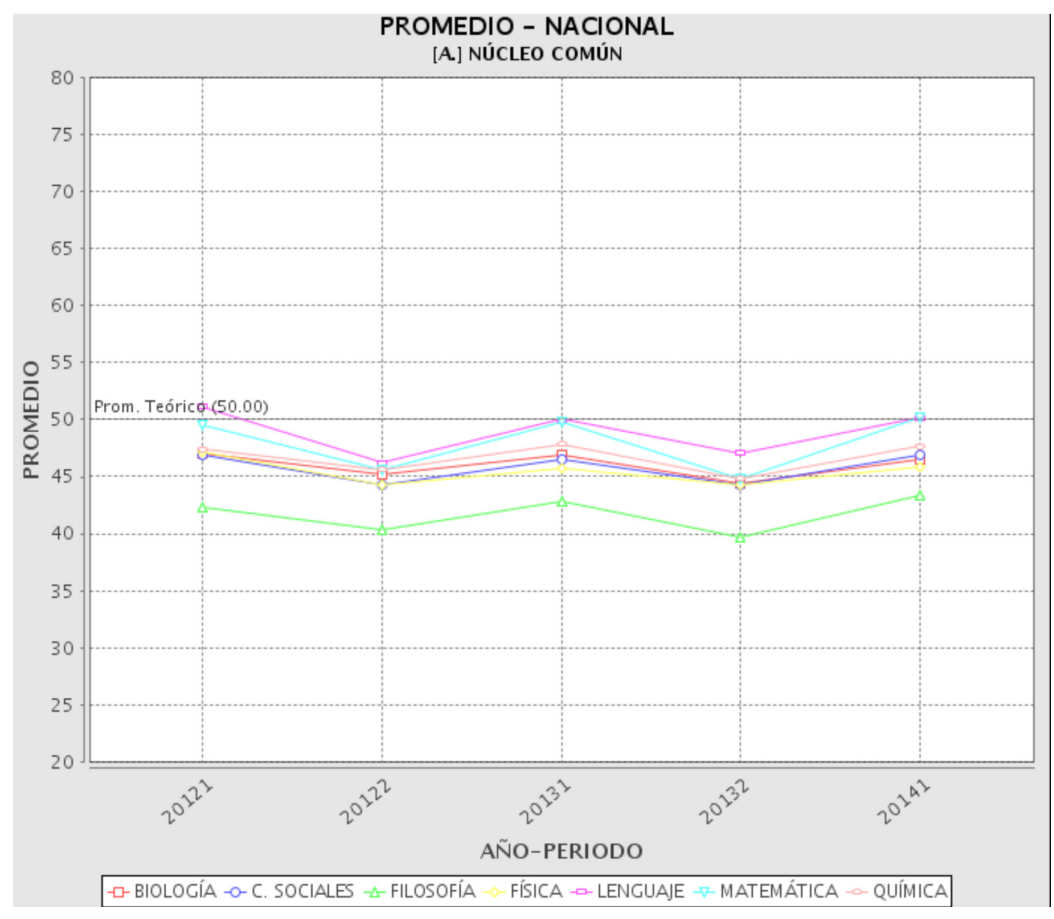

Fuente: Icfes. (2014). Resultado de Promedio Nacional en Pruebas del Estado en Educación. ICFES (2012-2014). Base de datos: Generador de Reportes Históricos. Recuperado el 2 de septiembre de 2014 de Icfes: http://www.icfesinteractivo.gov.co/ 
Frente a la primera pregunta planteada, los autores de El entorno negro de la educación en Bogotá. Radiografía de la educación pública en la ciudad desde una inmersión en el colegio distrital Santa Inés, determinaron que respecto de la implementación de los programas que crea el gobierno para promover el incremento en las tasas de escolaridad y calidad educativa, hay que mencionar que muchos de estos se ven truncados por el ambiente hostil en las familias de los menores, condicionando el rendimiento de los estudiantes y afectando la calidad educativa en nuestro país, por lo que concluyen que efectivamente la VIF hace parte de uno de los problemas para el desarrollo de la educación en Colombia (Rubio y Chagüi, 2003). A su vez, Cepeda, Moncada y Álvarez (2009), en Violencia intrafamiliar que afecta a estudiantes de educación básica y media en Bogotá, atribuyen como causas del fracaso de los programas del gobierno el hecho de que "en general no se abordan con profundidad aspectos relacionados con los contextos familiares y sociales del estudiante, que tienen gran incidencia en sus procesos de desarrollo" (p. 57).

En este mismo sentido, dentro de los autores que dedican parte de su investigación a responder la primera pregunta, Juanita Bernal, en Divorcio, violencia intrafamiliar y bienestar de los hijos indica que la VIF afecta el desempeño escolar de los niños (2008), y según el Programa de Convivencia Ciudadana de Medellín “acentúa problemas disciplinarios, lo que repercute directamente en su productividad futura y en el rendimiento de la inversión nacional en educación” (Medellín (Antioquia), 2000, p. 11). Un claro ejemplo de esto se muestra en la siguiente cifra presentada por Ribero y Sánchez (2004) en el estudio Determinantes, efectos y costos de la violencia intrafamiliar en Colombia: "los niños, niñas y jóvenes de hogares con violencia intrafamiliar experimentan cerca de 0.5 años de atraso escolar cuando se les compara con niños "prácticamente idénticos", pero que no sufren de violencia intrafamiliar" (p. 36). La gráfica 3 evidencia esta afirmación

\section{Gráfica 3. Niños con rezago escolar (\%), 2008}

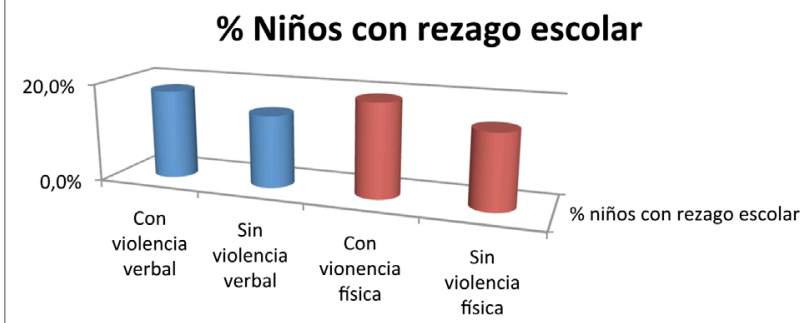

Fuente: elaboración propia con base en Bernal (2008), tabla 11.

En lo que concierne al segundo escenario, según el cual el descuido en el ámbito educativo ha sido cómplice de la VIF, el artículo El entorno negro de la educación en Bogotá. Radiografía de la educación pública en la ciudad desde una inmersión en el colegio distrital Santa Inés muestra la falta de atención adecuada a los casos de VIF. En él, Rubio y Chagüi (2003) denuncian que "muchos de los casos de abuso y de maltrato que padecen los estudiantes del Distrito pasan inadvertidos por las autoridades escolares" ( $p$. 11) o que cuando son descubiertos, "prefieren ser ocultados por quienes quieren privilegiar la imagen de la educación pública de la ciudad, sobre el reconocimiento de los problemas que afectan a sus jóvenes" (p. 9). 
En este mismo sentido, Claudia Caicedo (2005), en Lucha contra la violencia intrafamiliar: perspectivas desde la experiencia colombiana, ratifica que la falta de comunicación interinstitucional entre las autoridades judiciales/policivas y las educativas constituye una gran barrera para la detección de los casos de vif en colegios y escuelas, convirtiéndose en encubridor de la violencia dentro de las familias.

De cara a estas denuncias, resulta inevitable notar que existe un vacío y falta de interés en las secretarías de Educación para ayudar a controlar el fenómeno de la viF, pues en lugar de posicionarse como una institución activa y responsable en el manejo de los problemas que afectan el rendimiento escolar de los menores, dejan este deber y compromiso a otros entes que no tienen la posibilidad de incidir directamente sobre el bienestar de los niños, como son las comisarías de familia, ${ }^{11}$ que si bien fueron creadas para atender los casos de VIF en muchas ocasiones no tienen posibilidad de detectarlos.

Finalmente, respecto del tercer escenario, esto es, aquel que pretende ver en la educación una posible solución al fenómeno de la VIF, la tesis detrás de esta propuesta fue expuesta por Gaviria y Vélez (2001) en su estudio Who Bears the Burden of Crime in Colombia, en donde señalan que cada año de escolaridad reduce la probabi-

11 "Las Comisarias de Familia son autoridades de policía especializadas en materias de familia, las cuales adoptan medidas siguiendo procedimientos legales del Código de Familia. Dentro de las funciones de estas comisarias se encuentran: proteger a menores en situaciones de maltrato y explotación, recibir quejas e informes sobre aspectos relacionados con conflictos familiares internos, atender casos de VIF, aplicar sanciones policivas y dar apoyo al ICBF y otras autoridades" (Ribero y Sánchez, 2004, p. 34). lidad de ocurrencia de vIF en más de 0,7 puntos porcentuales.

Ahora, si bien es cierto que dentro del hogar pueden existir otras víctimas además de la mujer, por lo general los abusos van dirigidos hacia ella, y la posicionan como la víctima por excelencia de sus compañeros masculinos. En este sentido, se ha descubierto que entre más educación tenga la mujer es menos propensa a sufrir la VIF. La anterior afirmación es confirmada en las investigaciones Profiling domestic violence: A multy Country Study; La familia, reflexiones, cifras y legislación sobre violencia intrafamiliar; Who bears the burden of crime in Colombia; y Determinantes, efectos y costos de la violencia intrafamiliar en Colombia. Ribero y Sánchez (2004) aseguran que "las mujeres con más de 11 años de educación, muestran los niveles más bajos de ocurrencia de vIF" (p. 8), afirmación que es compartida por Kishor y Johnson (2004), quienes opinan que la educación disminuye en más de un punto porcentual la probabilidad de VIF en los hogares colombianos.

El primero de estos textos (Profiling domestic violence...) asegura que la educación funciona para todos los sujetos, pues no solo las mujeres que tienen más educación son menos propensas a ser víctimas, sino que también los hombres con niveles de educación adecuados son menos proclives a ser agresores, sugiriendo entonces que la educación funciona para ambas partes en relación con la violencia. Comprender esto último es de vital importancia para la formulación de políticas públicas dirigidas a mitigar la VIF, ya que erradicar el problema desde la 
raíz implica no solo atender a las víctimas, sino también tratar a los agresores para que la conducta no se repita con otros sujetos. Sus autores han dicho que "la educación funciona para todos los sujetos, pues no solo las mujeres que tienen más educación son menos propensas a ser víctimas, sino que también los hombres con niveles de educación adecuados son menos propensos a ser agresores" (Kishor y Johnson, 2004). Particularmente, Ribero y Sánchez (2004) corroboran lo anterior cuando apuntan que "alrededor del $50 \%$ de los casos en donde se presentó maltrato físico a los menores, ${ }^{12}$ la madre y su compañero tenían un bajo nivel educativo (escasamente habían terminado la primaria)" (p. 5).

En contraposición hay quienes opinan que no siempre los niveles de educación determinan la probabilidad de sufrir VIF. Felipe José Valencia en su tesis de grado Estadísticas y aspectos jurídicos de la violencia intrafamiliar, argumenta que en el campo hay menos educación, por lo que se tendería a pensar que hay más VIF, sin embargo, según datos del Instituto Nacional de Medicina Legal y Ciencias Forenses, el porcentaje de actos de VIF en la zona urbana es mucho mayor que en la rural $(86,6 \%$ frente al $6,2 \%)$, por lo que no se puede concluir que la educación incida en los niveles de VIF (Valencia, 2005, p. 36).

Si bien este es un punto de debate, no nos acogemos a esta explicación toda vez que deja por fuera del análisis el hecho de que en las zonas

12 Estos porcentajes corresponden a una encuesta realizada en tres ciudades colombianas a una población de cerca de 2300 mujeres. rurales la denuncia de estos abusos es menor que en la ciudad; incluso, hay pocas estadísticas que demuestren que las mujeres campesinas víctimas de VIF acuden en igual proporción a denunciar, que las víctimas de las metrópolis. Ningún otro estudio de los consultados para la elaboración del presente artículo sostiene esta posición.

En conclusión, como lo expresa Miguel Ángel Pérez, experto en educación, en la entrevista concedida a Diego Rubio y Ruby Chagüi, "la familia desempeña un papel muy importante en la educación. El entorno es definitivo en el proceso educativo, y en las clases bajas el entorno no ayuda, afecta" (Rubio y Chagüi, 2003, p. 11).

\section{SALUD Y VIOLENCIA INTRAFAMILIAR}

Cuando se habla de salud en un contexto de violencia se vuelve imperativo asumir una posición en extremo cuidadosa. Desde la visión del "desarrollo" su análisis se ha abordado en el marco de la salud pública, basándose en las consideraciones de organismos internacionales que buscan su mejoramiento para el avance socioeconómico de la humanidad. Por ejemplo, para el Banco Interamericano de Desarrollo (BID) existe una conexión inescindible entre salud y productividad económica ${ }^{13}$ toda vez que "la salud contribuye a la formación y preservación del capital humano" (BID, 1972, p. 1), mejorando y manteniendo la productividad de la fuerza

13 Nótese la visión de intervencionismo neoclásico del desarrollo explicada con anterioridad. 
laboral que vela por el crecimiento económico de los países. A su vez, autores como Cepeda y Caicedo (2007) y Caicedo (2005) entienden la VIF como un problema de salud pública que ha estado latente durante gran parte de la historia de la humanidad.

Por lo anterior, se decidió abordar la relación entre salud y VIF como un problema de salud pública. Este enfoque hace parte de la política promovida por la Organización Mundial de la Salud (oms), organismo que en una serie de recomendaciones a los países del mundo ha insistido en que "los gobiernos deben comprometerse a reducir la violencia en el hogar, ya que se trata de un importante problema de salud pública que debe prevenirse" (2005, p. 28).

Empero, vale la pena preguntarse: ¿qué se entiende por salud pública? y ¿por qué adoptar esta visión? La Organización Panamericana de la Salud (ops) en su Informe mundial sobre violencia y salud explica que

por definición, la salud pública no se ocupa de los pacientes a título individual. Su interés se centra en tratar las enfermedades, afecciones y problemas que afectan la salud de todas las poblaciones en general. Esta, pretende proporcionarle el máximo beneficio para el mayor número posible de personas desde estrategias interdisciplinarias (2003, p. 3).

Adoptar esta visión significa preocuparse por los costos reales que genera la VIF en términos sociales y económicos. Este enfoque, como bien lo indica el Programa de Convivencia Ciudadana de Medellín (2000), aboga por una política de intervención y constituye una perspectiva ampliamente consolidada que pretende prevenir la violencia a través de la reducción de los factores de riesgo, haciendo uso de distintos tipos de monitoreo y desarrollando estrategias para modificar los comportamientos tanto en los grupos poblacionales como en los individuos.

Aterrizando los anteriores conceptos al caso de estudio, se determina que para adoptar la tesis de la salud pública como un factor influyente en la lucha por erradicar la vif debe asumirse una visión integral del problema, como se propuso con anterioridad. ¿Qué quiere decir que sea integral? Para ser más precisos, que genera costos económicos monetarios y no monetarios. Los primeros son representados en atención en salud, los cuales incluyen afiliaciones a EPS, atención médica, dictámenes de medicina legal, hospitalizaciones y gastos en medicamentos. Los segundos, se refieren a la pérdida de años de vida saludable, peores indicadores de salud para mujeres y niños, desnutrición y una disminución de la calidad de vida en general.

Los siguientes datos ilustran lo dicho:

- Kishor y Johnson (2004) encontraron que en Colombia el $28 \%$ de los casos de VIF reportan haber recurrido a asistencia médica tras un episodio de esta naturaleza.

- El Instituto Nacional de Medicina Legal y Ciencias Forenses en el 2011 reportó 89.807 casos de VIF, 371 más que en el 2010, y precisó que la tasa nacional de VIF fue de 195.04 casos reportados por cada 100.000 habitantes. 
- Caicedo (2005) en un cálculo realizado para el 2002 determinó que la pérdida en años de vida saludable de las víctimas fue de 85,079 .

- Ribero y Sánchez (2004) establecieron que en el año 2003 un total de "200.000 personas sufrieron de problemas de salud debido a la violencia contra la mujer, entre la cual se incluye la VIF. Suponiendo que estas personas acudieron a los servicios médicos, con la probabilidad promedio de consulta implícita en la UPC, y que se gastaron 269.000 pesos por evento, se encuentra que los costos en salud asociados a la violencia contra la mujer ascendieron a $54 \mathrm{mil}$ millones de pesos" (p. 29). Estos datos deben haber aumentado, dado el incremento de casos reportados.

Lo anterior es solo un abrebocas de la consideración sobre los costos, pues, como se ha expresado a lo largo del artículo, no existe un informe actual que arroje datos completos sobre los costos reales de la vif. A pesar de ello, lo que se ha expuesto hasta el momento logra dejar una preocupación enorme frente a los costos en salud que implica el problema de la vif. Resulta entonces pertinente referirnos a la pregunta que se ha hecho la ops: ¿cómo adoptar el enfoque de salud pública? Esta Organización sugiere un modelo de tres etapas: 1) prevención, 2) respuestas inmediatas e 3 ) intervención a largo plazo (ops, 2003). El objetivo de estos tres pasos es actuar conjuntamente, ya que, como se vio, día a día se generan costos monetarios y no monetarios insoportables para la sociedad colombiana. ${ }^{14}$

Podría pensarse en un análisis económico de la política pública de salud que busque atender el problema de la VIF desde la consideración que los costos en prevención pueden llegar a ser menores que los que se derivan de la atención del daño causado por la viF, puesto que no sería razonable dejar como un tema velado el análisis de la vif en relación con el desarrollo económico del país.

\section{DESEMPLEO, PRODUCTIVIDAD LABORAL Y VIOLENCIA INTRAFAMILIAR}

El binomio de productividad laboral y VIF puede analizarse simultáneamente desde dos perspectivas: como causa y como consecuencia. Es decir, el desempleo, la inestabilidad laboral y la mala situación económica contribuyen a la permanencia de la viF. Al mismo tiempo, puede pensarse en la viF como catalizador de los problemas que afectan las variables del mercado laboral.

Varios de los estudios aquí mencionados, entre ellos: La familia, reflexiones y cifras sobre violencia intrafamiliar; Transmisión intergeneracional de la violencia intrafamiliar: evidencia para las familias colombianas; La mujer y la infancia afectados principales en los casos de violencia intrafamiliar; y Determinantes, efectos y costos de la violencia intrafamiliar en Colombia, han

14 Insoportables en el sentido de que no hay dinero para afrontarlos. 
expuesto que la poca demanda en el mercado laboral o desempleo genera niveles altísimos de estrés dentro de la familia, lo que conlleva a respuestas violentas contra los miembros que permanecen más tiempo en el hogar y que no tienen una posición dominante en su estructura interna.

Luz Magdalena Salas en su texto Transmisión intergeneracional de la violencia intrafamiliar, ahonda en este tema preguntándose: ¿cuáles son las consecuencias de dicho estrés? En el caso de la mujer -quien es la víctima más frecuente de VIF -, económicamente hablando, puede pensarse en una disminución de la productividad laboral, una mayor posibilidad de desempleo y una mengua en el salario recibido (2005, p. 21).

En resumidas cuentas, el estrés producido por las causas mencionadas genera violencia doméstica afectando la vida laboral de la víctima, ya que todos estos elementos se encuentran conectados entre sí. Como bien lo expresa el estudio Fortalecimiento de la convivencia familiar, prevención y atención de la violencia intrafamiliar: esquema para Medellín, "las mujeres que sufren de violencia doméstica tienen índices más altos de ausentismo laboral y disminución en la productividad, lo que implica una mayor probabilidad de ser despedidas del trabajo y una pérdida directa para la producción nacional" (Medellín (Antioquia). Programa de Convivencia Ciudadana, 2000, p. 11), y en palabras de Ribero y Sánchez (2004), "si en un hogar existe maltrato severo, los ingresos laborales de la mujer se reducen, son inferiores en cerca de
300.000 pesos (-70\% menos) de los que serían si no existiera violencia intrafamiliar" (p. 1). Lo cual para la Consejería para la Equidad de la Mujer de la Presidencia de la República (2005) constituye un menoscabo en los ingresos del hogar y por tanto en el ingreso nacional.

Una de las soluciones que se ha propuesto en estudios de desarrollo como, por ejemplo, Profiling domestic violence: A Multy-Country Study, ha sido la de incentivar y garantizar el empleo tanto para la posible víctima como para el potencial victimario. En el caso de las mujeres, Kishor y Johnson, sus autoras, afirman que aquellas que gozan de un empleo y ganan un salario sufren menos de VIF, dado que se empoderan y dejan la calidad de víctimas (2004). De esta manera, dicen ellas, se genera una mayor posibilidad para la víctima de poder tomar decisiones propias que procuren su bienestar, sin tener que estar subyugada por depender económicamente del agresor. ${ }^{15}$

En el caso de los hombres, Ribero y Sánchez (2004) afirman que aquellos que están menos ocupados tienden a ser más agresores, de ahí que su hipótesis sea que la viF es consecuencia del desempleo, como lo prueban los resultados de su investigación: "el porcentaje de esposos o compañeros empleados en los hogares sin VIF es de $91 \%$, mientras que en los hogares con VIF es significativamente menor" (p. 13), lo que los Ileva a concluir que si el agresor trabaja, la incidencia de VIF es pequeña. Por lo tanto, considerar el desempleo como uno de los factores de

15 Recuérdese la tesis de la teoría de la dependencia económica. 
la VIF resulta de vital importancia a la hora de diseñar políticas públicas encaminadas a amainar el fenómeno.

Ahora bien, es pertinente mencionar que existe debate respecto a las posiciones y soluciones planteadas. Hay quienes sostienen que empoderar a la víctima mediante un trabajo y un salario no constituye una solución al problema de la VIF. Por ejemplo, Kishor y Johnson (2004) aseveran que las mujeres con salarios son más propensas a sufrir de VIF, afirmación que sustentan en los datos arrojados por su estudio, pues encontraron que aquellas mujeres que reportaron tener un empleo y ganar dinero experimentaron niveles más altos de viF.

Aunque resulta paradójica la anterior afirmación, hay que resaltar que este estudio se centró más en la recolección de datos que en un análisis profundo sobre estos en cada país de la muestra; es decir, se proponen análisis globales que dejan por fuera consideraciones tales como el contexto cultural, social, económico, entre otros, de cada país. Antes que desconocer sus datos lo que resulta importante concluir es la inconveniencia de centrarse en una sola política cuando de buscar la solución al problema se trata; las soluciones a la VIF deben ser multidisciplinarias, pues no es posible acabar con el problema actuando desde un único frente de acción.

\section{ANÁLISIS DE LA ENCUESTA NACIONAL DE DEMOGRAFÍA Y SALUD (ENDS): AÑOS 2000, 2005 Y 2010}

Este aparte pretende señalar algunas de las fallas en las que se ha incurrido en la medición de encuestas, tales como la ENDS, y que no han permitido sacar datos coherentes y contundentes para analizar la VIF.

La primera objeción es que resulta difícil hacer una comparación justa entre los datos obtenidos entre una y otra encuesta. Esto se debe a que en las ENDS, el tamaño de las muestras es significativamente diferente entre una y otra. Por dar un ejemplo, en el año 2005 la muestra de mujeres sin educación fue casi el triple que la muestra equivalente en el año 2000. Por este motivo, sin un análisis estadístico pertinente es difícil decir si estas medias son directamente comparables.

La inquietud que surge frente a este problema podría encontrar solución en la inclusión de este tipo de muestreos en los censos que se hacen en Colombia, ya que los datos obtenidos aspirarían a representar a toda la población y no a un número arbitrario que se escoge en las ENDS.

La segunda objeción es que cada encuesta tiende a medir cosas distintas. Por ejemplificar la situación: la ENDS del 2000 recopiló información sobre el tipo de golpes en relación con el nivel de educación, mientras que la ENDS 2005 relacionó el tipo de golpes con el nivel de ingreso. 
Se concluye entonces que el análisis, además de limitado. es en extremo complicado.

\section{COSTOS DE LA VIOLENCIA INTRAFAMILIAR EN TÉRMINOS GENERALES PARA COLOMBIA}

La violencia intrafamiliar no es un problema menor por los costos que representa no solo en capital humano, sino también para la economía del país. Hasta ahora se ha visto cómo la VIF influye en el campo de la educación, la salud y el empleo, generando en cada uno costos inmensurables. Estos costos, como ya se dijo, son de dos tipos: directos e indirectos, o monetarios y no monetarios. A continuación, se hará un breve recuento de ellos según cada una de las categorías estudiadas sobre desarrollo. Es importante aclarar que desde el estudio realizado por Ribero y Sánchez (2004), investigadora y director del CEDE respectivamente, no se han vuelto a hacer intentos por cuantificar monetariamente los efectos de la VIF, por lo que los resultados que se presentan pueden estar desactualizados a hoy día.

\section{A. Salud}

- Contempla atención médica, medicamentos, infraestructura hospitalaria, capacitación de personal, programas de prevención, atención inmediata en urgencias, atención psicológica, pérdida en años de vida, disminución de la calidad de vida y propensión a enfermedades, entre otros.
- "En conjunto, el costo de la violencia intrafamiliar por peor salud en la mujer y en los niños alcanza más de 339 mil millones equivalentes al 0,15\% del PIB del año 2003" (Ribero y Sánchez, 2004, p. 29).

- "Lo que se gastan los hogares en ingresos por consecuencias de salud de quienes padecen de violencia intrafamiliar equivalen a 8,764 billones de pesos en 2003; cerca del 3,9\% del PIB del país" (Ribero y Sánchez, 2004, p. 29).

\section{B. Educación}

- Contempla la pérdida de la inversión en educación a nivel nacional, pues la calidad educativa no mejora si los niños se encuentran bajo vif.16

- Incluye la pérdida de productividad del menor que llega a adulto sin la preparación adecuada para la vida laboral y social (Rubio y Chagüi, 2003).

- Incrementa el nivel de años requeridos para poder cumplir el ciclo escolar (Ribero y Sánchez, 2004).

- Circunscribe los costos que deben ser destinados para la prevención, atención y capacitación del docente y en general del personal del plantel educativo (Rubio y Chagüi, 2003).

16 Esta afirmación pertenece a la posición en la academia que cree que la VIF constituye un problema para el desarrollo de la educación en Colombia. Ver numeral III. Violencia intrafamiliar y educación, de este estudio. 
- Sacrifica los estándares de cobertura y calidad educativa en el país (Rubio y Chagüi, 2003).

- Arraiga el fenómeno de vif, pues como quedó demostrado, entre menor es el nivel educativo, mayor propensión hay de sufrirla (Gaviria y Vélez, 2001).

\section{Mercado laboral}

- Disminuye los ingresos salariales de mujeres y hombres que viven situaciones de VIF. "Esta disminución se estima en un 70\% en comparación con las familias que no sufren de vIF" (Ribero y Sánchez, 2004, p. 29).

- "Los ingresos laborales dejados de percibir representan para el año 2003 aproximadamente 7.5 billones de pesos equivalentes al 3,4\% del PIB colombiano" (Ribero y Sánchez, 2004, p. 29).

- Implica una pérdida en la capacidad laboral, un aumento del desempleo y una inestabilidad laboral que impide que las familias marginadas por la VIF superen dicha situación (Medellín (Antioquia). Programa de Convivencia Ciudadana, 2000).

- "La violencia severa contras las mujeres deja un número de desempleados de 360 mil cada año" (Ribero y Sánchez, 2004, p. 29).

- "El maltrato severo a menores aumenta el desempleo femenino de 75 mil mujeres por año" (Ribero y Sánchez, 2004, p. 29).
Otro costo importante para la economía nacional, que se mencionó con anterioridad pero vale la pena reiterar, es el institucional, el cual incluye los gastos por VIF en los que incurren entidades tales como el Instituto Nacional de Medicina Legal y Ciencias Forenses, el Instituto Colombiano de Bienestar Familiar y la Fiscalía General de la Nación.

Se debe advertir que el siguiente recuento de datos solo se refiere a la investigación realizada por Ribero y Sánchez en el 2004, por lo que al día de hoy lo más seguro es que las cifras hayan variado. Sin embargo, la finalidad es dar al lector una visión general de lo que económicamente significa para el país la vif.

Entrando en materia, en el 2003, del presupuesto asignado a cada una de estas entidades, el ICBF gastó solo en programas de prevención 136.349.050.634 millones de pesos. Por su parte, el Instituto Nacional de Medicina Legal y Ciencias Forenses invirtió 16.475.913.635 miIlones en tratamiento y atención, lo cual suma (de acuerdo con el presupuesto del 2002) más del $18 \%$ del presupuesto ejecutado por esa institución. Finalmente, la Fiscalía General de la Nación empleó 42.639.948.370 millones de pesos en atención a los casos de VIF. Todas las cifras anteriores junto con otros gastos asociados significaron para el país 196.609.589.799 millones de pesos en el 2003 (Ribero y Sánchez, 2004, p. 34). 
Cuadro 1. Costos directos del Estado por violencia intrafamiliar

\section{Cuadro 14. Costos Totales}

\begin{tabular}{lc}
\hline $\begin{array}{l}\text { Costos Directos del Estado, Consolidado 2002 } \\
\text { Violencia Intrafamiliar }\end{array}$ & $\begin{array}{c}\text { Total } \\
\text { Ejecutado }\end{array}$ \\
\hline Instituto Colombiano de Bienestar Familiar ICBF & $136,349,050,634$ \\
Subsecretaria para asuntos de seguridad y convivencias ciudadanas & $1,144,677,160$ \\
Fiscalía General de la Nación & $42,639,948,370$ \\
Instituto Nacional de Medicina Legal & $16,475,913,635$ \\
\hline TOTAL & $196,609,589,799$ \\
\hline
\end{tabular}

Nota: Cifras en millones de pesos de 2003.

Fuente: Ribero, R. y Sánchez, F. (2004). Determinantes, efectos y costos de la violencia intrafamiliar en Colombia. Bogotá: CEDE, Universidad de los Andes.

Estos últimos datos solo representan los costos monetarios del fenómeno de VIF, por lo que a lo anterior habría que sumarle otros miles de millones de pesos si se pudiesen cuantificar los costos no monetarios que se han mencionado con antelación.

\section{CONCLUSIONES}

Para finalizar, se hace énfasis en unos puntos claves del trabajo. El primero de ellos consiste en el vacío en términos de producción académica y estadística sobre la incidencia de la vif en el desarrollo económico y social colombiano. Como habrá sido evidente, los datos referidos son de años atrás, por lo que conocer en qué términos está el fenómeno actualmente es en extremo difícil. Es preciso aclarar que la laguna se debe no solo a la falta de información, sino también a la falta de análisis de los datos arrojados por el gobierno y por entidades independientes que tratan de rastrear el problema. Incluso la propia Administración ha manifestado que a pesar de los altos índices registrados en relación con la violencia intrafamiliar, sabemos que el sub-registro es muy alto, situación que se presenta por varios motivos. Como por ejemplo la normalización, la insuficiente cultura de denuncia por la insuficiente divulgación de la legislación que previene y sanciona la violencia doméstica y el temor a las represalias por parte de los victimarios, entre otras" (Garzón, 2005, p. 90).

A estas explicaciones habría que sumarle la posible falta de interés y de apoyo para darle continuidad a las investigaciones que han tratado de asumir el reto propuesto en este escrito.

Ahora bien, no sobra recordar la razón por la cual el nexo entre VIF y desarrollo resulta tan importante y necesario: "los cambios en las relaciones interfamiliares no solo son resultado de voluntades e intereses individuales, sino de procesos socio-económicos que afectan el desarrollo familiar" (Palacio, 1982, p. 197). Procesos socioeconómicos tales como la inequidad, la miseria, la inestabilidad laboral, la insatisfacción de necesidades básicas, la falta de educación, los problemas en salud, entre otros, son en sí mismos expresiones de violencia que contri- 
buyen a los abusos que se producen al interior de la familia, a privaciones en el desarrollo vital humano, a la acumulación de tensiones y frustraciones, a la falta de reconocimiento social y la consecuente exclusión (Medellín (Antioquia). Programa de Convivencia Ciudadana, 2000, p. 12). De ahí que se insista en enfrentar la VIF desde todos los flancos del desarrollo.

De otra parte, fue posible observar cómo la VIF actúa como un círculo vicioso, ya que se manifiesta como causa y a la vez como consecuencia de los problemas que aquejan a las familias colombianas. Aquí se genera la necesidad de estructurar planes integrales contra la viF que incluyan propuestas desde la educación, la salud, el empleo y desde el ataque a la pobreza. Se sabe que la inversión requerida es alta; sin embargo, si se mira desde una perspectiva a largo plazo, deberá analizarse si resulta más el ahorro que el gasto, pues como se acreditó, los gastos monetarios y no monetarios para el desarrollo del país son cuantiosos si se continúa conviviendo con la VIF.

Del mismo modo, se reitera la necesidad de incluir en los censos nacionales la medición de la VIF en relación con las categorías de desarrollo. Esto, junto con un análisis completo y juicioso de los valores estadísticos, ya que a partir del estudio de las ENDS, fue posible darse cuenta de que no hay un estudio constante que evalúe el progreso o retroceso en la disminución de la viF en el país.

Especulando sobre la deficiencia en la información, podría llegar a pensarse que la división entre lo público y lo privado sigue siendo una consideración importante a la hora de evaluar las familias, y, por tanto, acceder a datos estadísticos sobre una institución tan hermética como esta ha sido en extremo difícil. Igualmente, no puede dejar de considerarse la falta de preocupación o de interés sobre este tema, en particular por parte de los economistas, abogados, ingenieros $y$, en general, de todos los que manejan la planeación nacional del Estado.

En cuanto a lo desactualizados que puedan estar los datos, una hipótesis que se podría construir al respecto sería aquella por la cual si los casos de VIF reportados por Medicina Legal se han incrementado, podría pensarse que proporcionalmente lo ha hecho el gasto nacional en la prevención y tratamiento del fenómeno. No obstante, estos son datos que deben ser comprobados por una experticia que supera los límites de este trabajo, por ello se invita de manera cordial a que los correspondientes análisis se desarrollen.

Todo lo anterior pensando en que la finalidad del desarrollo es el logro de plenos e iguales derechos para todos y cada uno de los ciudadanos en nuestro país, y que para alcanzar dicha finalidad es necesario sobreponerse a obstáculos como el que representa la vif. Sobrepasarlos desde todos los ámbitos que permean al ser humano, como son los que se desarrollaron en el presente artículo. 


\section{Referencias}

Alviar, H. (2008). Derecho, desarrollo y feminismo en América Latina. Bogotá: Temis.

Alviar, H. (2011). Legal Reform, Social Policy and Gendered Redistribution in Colombia: The Role of the Family. American University Journal of Gender Social Policy and Law, 19(2). Obtenido de Journal of Gender, Social Policy \& the Law: http://digitalcommons.wcl.american.edu/cgi/viewcontent. cgi?article=1516\&context=jgspl

Banco Interamericano de Desarrollo. (Junio de 1972). Política de salud pública del Banco Interamericano de Desarrollo. Recuperado el 19 de febrero de 2013, de BID: http://www. iadb.org/es/acerca-del-bid/politica-de-saludpublica-del-banco-interamericano-de-desarroIlo,6222.html

Bernal, J. (2008). Divorcio, violencia intrafamiliar y bienestar de los hijos. (Tesis para obtener el título de economista). Obtenido de biblioteca.uniandes: (https://biblioteca.uniandes.edu.co/visor_de_tesis/web/?SessionID= L1RIc2IzXzlyMDA4X3NIZ3VuZG9fc2VtZXNOc mUvMTIxOC5WZGY\%3D)

Caicedo, C. (Diciembre de 2005). Lucha contra la violencia intrafamiliar: perspectivas desde la experiencia colombiana. Recuperado el 22 de agosto de 2012, de eip-cifedhop: http:// www.eip-cifedhop.org/publications/thematique13/Caicedo.pdf
Cebotarev, E. (1994). Mujeres, derechos humanos y familia en la teoría y práctica del desarrollo. En E. Cebotarev, Mujer, familia y desarrollo. (págs. 83-108). Manizales: Universidad de Caldas.

Cepeda, E. y Caicedo, G. (2007). Factores asociados a la calidad de la educación. Revista Iberoamericana de Educación, 43(4), 1-7.

Cepeda, E., Moncada, E. y Álvarez, V. (2009). Violencia intrafamiliar que afecta a estudiantes de educación básica y media en Bogotá. Revista de Salud Pública, 9(4), 516-528.

Departamento Administrativo Nacional de Estadística. (Agosto 14 de 2013). Boletín de Prensa: Comportamiento del mercado laboral por sexo. Trimestre abril - junio de 2013. Recuperado el 2 de septiembre de 2014 de DANE: https://www.dane.gov.co/files/investigaciones/boletines/ech/ech_genero/bol_sexo_ abr_jun13.pdf

Departamento Nacional de Planeación. (Junio de 2013). Comportamiento del mercado laboral por sexo. Obtenido de DANE: https://www. dane.gov.co/files/investigaciones/boletines/ ech/ech_genero/bol_sexo_abr_jun13.pdf

Departamento Nacional de Planeación, Banco Interamericano de Desarrollo y Universidad de los Andes. (2004). Violencia en las familias colombianas: costos socioeconómicos, causas y efectos. Bogotá: Colección Justicia y Seguridad. 
Gallardo, C. (Septiembre de 2003). Trabajo reproductivo y productivo en el Ecuador. Obtenido de Cepal: http://www.cepal.org/mujer/ reuniones/tiempo/tm_ecuador.pdf

Garzón, C. S. (1990). Diagnóstico de género para la población de soacha, con énfasis en las mujeres desplazadas. Bogotá: Unifem. Obtenido de ACNUR: http://www.acnur.org/t3/ fileadmin/scripts/doc.php?file=t3/fileadmin/ Documentos/Publicaciones/2006/4088

Gaviria. A. y Vélez, C. (Enero de 2001). Who Bears the Burden of Crime in Colombia? Obtenido de Social Science Research Network: http://papers.ssrn.com/sol3/papers. cfm?abstract_id=256746

Instituto Colombiano para el Fomento de la Educación Superior. (2014). Generador de reportes de datos históricos. Obtenido de Icfes mejor saber: http://www.icfesinteractivo.gov.co/

Instituto Nacional de Medicina Legal y Ciencias Forenses. (2011). Comportamiento de la violencia intrafamiliar 2011. Obtenido de medicinalegal: http://www.medicinalegal.gov.co/ images/stories/root/FORENSIS/2011/4-F11-VIF.pdf

Kishor, S. y Johnson, K. (2004). Profiling Domestic Violence: A Multy-Country Study. Obtenido de measuredhs: http://www.measuredhs. com/pubs/pdf/od31/od31.pdf

Lalasz, R. (2004). Violencia en los países en desarrollo: una crisis intergeneracional. Obtenido de Population Reference Bureau:
http://www.prb.org/SpanishContent/Articles/2004/LaViolenciaFamiliarEnLosPaisesEnDesarrolloUnaCrisisIntergeneracional.aspx

Ministerio de Educación Nacional. (2012). Presupuesto General de la Nación para la Vigencia Fiscal de 2012. Obtenido de mineducacion: http://www.mineducacion.gov.co/1621/articles-95818_archivo_presupuesto_2012.pdf

Ministerio de Hacienda y Crédito Público. (2013). Comunicado de prensa 28. Presupuesto General de la Nación 2013: hacia un desempeño eficaz del Estado. Obtenido de minhacienda: http://www.minhacienda.gov.co/portal/ pls/portal/docs/1/5886730.PDF

Ministerio de Hacienda y Crédito Público. (2014). Presupuesto General de la Nación 2014. Obtenido de minhacienda: http://www. minhacienda.gov.co/portal/page/portal/HomeMinhacienda/presupuestogeneraldelanacion/ProyectoPGN/2014/PRESUPUESTO\%20 GRAL\%202014.pdf

Medellín (Antioquia). Programa de Convivencia Ciudadana. (2000). Fortalecimiento de la convivencia familiar, prevención y atención de la violencia intrafamiliar: esquema para Medellín. Medellín: Alcaldía de Medellín.

Oficina del Alto Comisionado de las Naciones Unidas para los Derechos Humanos. (2006). Preguntas frecuentes sobre el enfoque de Derechos Humanos en la cooperación para el desarrollo. Obtenido de ohcrh: http://www.ohchr.org/Documents/Publications/FAQsp.pdf 
Organización Panamericana de la Salud. (2003). Informe mundial sobre la violencia y la salud. Obtenido de paho.org: http://whqlibdoc.who. int/publications/2003/9275315884_spa. pdf

Organización Mundial de la Salud. (2005). Estudio multipaís de la oms sobre salud de la mujer y violencia doméstica. Obtenido de who. int: http://www.who.int/gender/violence/ who_multicountry_study/summary_report/ summaryreportSpanishlow.pdf

Osorio, R. y Arias, L. (1989). Mujer, familia y violencia: hablamos desde las mujeres. En Asociación de Antropólogos Egresados de la Universidad de Antioquia, Familia y cambio en Colombia: las transformaciones de fines del siglo XX. (págs. 181-195). Medellín: Asociación de Antropólogos egresados de la Universidad de Antioquia.

Palacio, M. (1982). Violencia y familia. En Asociación de Antropólogos Egresados de la Universidad de Antioquia, Familia y cambio en Colombia: las trasformaciones de fines del siglo XX. (págs. 197-207). Medellín: Asociación de Antropólogos Egresados de la Universidad de Antioquia.

Presidencia de la República y Consejería para la Equidad de la Mujer. (2005). Política afirmativa "Mujeres Constructoras de Paz y Desarrollo". Obtenido de americalatinagenera: http://www.americalatinagenera.org/es/index.php?option $=\mathrm{com}_{-}$ content\&task=view\&id=199\&exp_id=692\&m $\mathrm{I}=1 \& \mathrm{mlt}=$ system $\& \mathrm{tmp} \mid=$ component

Alcaldía Mayor de Bogotá. (2005). Plan de igualdad de oportunidades para la equidad de género en el Distrito Capital 2004-2016. Obtenido de http://www.sdp.gov.co/portal/ page/portal/PortalSDP/SeguimientoPoliticas/Pol\%EDticaPublicaDeMujeresyEquidad DeG\%E9nero/QueEs/PIOEG.PDF

Presidencia de la República y Observatorio de Asuntos de Género. (Sept.-Dic. 2004). Maltrato y violencia: reflexiones de una experta. Revista Asuntos de Género, 1(2), 15-16. Obtenido de equidadmujer: http://www.equidadmujer.gov.co/Publicaciones/oag_boletin_2.pdf

Redacción política El Tiempo. (16 de julio de 2012). Presupuesto de inversión record: 70\% irá para temas sociales. Obtenido de eltiempo.com: http://www.eltiempo.com/ politica/ARTICULO-WEB-NEW_NOTA_INTERIOR-12034362.html

Ribero, R. y Sánchez, F. (2004). Determinantes, efectos y costos de la violencia intrafamiliar en Colombia. Bogotá: CEDE, Facultad de Economía de la Universidad de los Andes.

Rubio, D. y Chagüi, R. (2003). El entorno negro de la educación en Bogotá. Directo Bogotá, I(2), 9-16.

Salas, L. M. (2005). Transmisión intergeneracional de la violencia intrafamiliar: evidencia 
para las familias colombianas. Recuperado el 4 de junio de 2012, de Universidad de los Andes: http://economia.uniandes.edu. co/investigaciones_y_publicaciones/CEDE/ Publicaciones/documentos_cede/2005/ transmision_intergeneracional_de_la_violencia_intrafamiliar_evidencia_para_las_familias_colombianas
Valencia, F. (2005). Estadísticas y Aspectos Jurídicos de la Violencia Intrafamiliar. (Tesis de pregrado). Universidad Colegio Mayor de Nuestra Señora del Rosario, Bogotá.

Vylder, S. de. (2005). Poniendo fin a la violencia de género: un llamado a la acción global para involucrar a los hombres. Obtenido de unfpa: http://www.unfpa.org.sv/dmdocuments/violencia_genero_varones.pdf 